Original Article

\title{
EVALUATION OF PRESCRIBING INDICATORS FOR PEADIATRIC OUTPATIENTS UNDER SIX YEARS OLD IN DISTRICT HOSPITALS OF CAN THO CITY IN THE PERIOD OF 2015-2016
}

\author{
HUNG PHUC NGUYEN1, HUONG VO THI MY1, THANH PHAN CHI²
}

${ }^{1}$ Faculty of Pharmacy, Can Tho University of Medicine and Pharmacy, Can Tho city 900000 , Vietnam, ${ }^{2}$ Can Tho general hospital, Can Tho city 900000 , Vietnam

Email: nphung@ctump.edu.vn

Received: 04 Jan 2019 Revised and Accepted: 02 May 2019

\section{ABSTRACT}

Objective: Examining and comparing the primary and supplementary prescribing indicators in pediatric outpatients under six years old.

Methods: We performed a comparative cross-sectional study, over nine months, from September 2015.800 prescriptions for peadiatric patients under 6 y old were collected at 8 district hospitals in Can Tho city to evaluate the primary and supplementary prescribing indicators. The sample was collected prospectively by the systematic selection, with the interval between the patients is 5 . The data was analysed and compared to the standard drug use indicators in developing countries recommended by WHO.

Results: Average number of drugs per encounter: 4.1, percentage of drugs prescribed by generic name: $94.2 \%$, percentage of encounters with an antibiotic prescribed: $85.8 \%$, percentage of drugs prescribed from essential drugs list by Ministry of Health: $78.7 \%$, percentage of encounters with a corticoid prescribed: $41.7 \%$, percentage of encounters with a vitamin prescribed: 13.1\%, average drug cost per encounter: 37.5 thousands VND percentage of drug costs spent on antibiotics: $55.2 \%$, percentage of drug costs spent on essential drugs: $75.7 \%$, percentage of drug costs spent on corticoid: $1.9 \%$, percentage of drug costs spent on vitamin: $1.4 \%$.

Conclusion: The results of this research have identified some issues in outpatient prescribing, which may lead to intervention studies for evaluating changes in these issues in the outpatient clinic.

Keywords: Prescription, Primary prescribing indicators, Supplementary prescribing indicators

(C) 2019 The Authors. Published by Innovare Academic Sciences Pvt Ltd. This is an open access article under the CC BY license (http://creativecommons.org/licenses/by/4.0/) DOI: http://dx.doi.org/10.22159/ijpps.2019v11i6.31852

\section{INTRODUCTION}

Human requirements for healthcare increased with the level of social development. However, irrational prescription and drug use have been a matter of concern in most countries because of serious consequences for the economy and society. The overuse of drugs, especially antibiotics, vitamins and corticoids, were popular occurrences in many countries. Children are among the most vulnerable part of our society. Medication errors cause more harm in children compared to adult counterparts [1].

Like developing countries, the drug overuse in Vietnam is also an emerging issue. In Bachmai Hospital, a research by Tran Nhan Thang (2012) on 3,971 outpatients who were prescribed showed that the average number of drugs was 4.7 and approximately $32.3 \%$ of all prescriptions had antibiotics [2]. Can Tho, a central city in Mekong Delta region, to the best of our knowledge, there is no comprehensive evaluation of the prescribing indicator. Eight loca hospitals which located at the urban of Can Tho city haven't got good conditions and infrastructure for healthcare. Therefore, we conducted this study to investigate the prescription issues in these public medical section. Our main objective was to evaluate and compare the drug prescription parameters with World Health Organization (WHO) standards in peadiatric outpatients under six years old at district hospitals of Can Tho city in the period of 2015-
2016 and the harmful potential induced by errors in using drugs for childrenis three times higher than for adults [3]

\section{MATERIALS AND METHODS}

Study design

A comparative cross-sectional study was conducted. We collected 880 prescriptions for peadiatric patients under 6 y of age visited 8 district hospitals in Can Tho city (100 prescriptions in each hospital), in which the error of the data collection process was $10 \%$ [4]. Prescriptions were selected by prospective method-i.e. collecting prescriptions on the right day of the study.

\section{Data collection}

The primary prescribing indicators were assessed, including average number of drugs per encounter, percentage of drugs prescribed by generic name, percentage of encounters with an antibiotic prescribed, percentage of drugs prescribed from the essential drugs list by Ministry of Health, percentage of encounters with a corticoid prescribed, and percentage of encounters with a vitamin prescribed The same process was performed with the supplementary prescribing indicators which consists of average drug cost per encounter, percentage of drug costs spent on antibiotics, percentage of drug costs spent on essential drugs, percentage of drug costs spent on corticoid, and percentage of drug costs spent on a vitamin.

\section{RESULTS}

Table 1: The results of primary prescribing indicators

\begin{tabular}{|c|c|c|c|c|c|c|c|c|c|}
\hline & Mean & Binh Thuy & Cai Rang & O Mon & Thot Not & Co Đo & Phong Đien & Thoi Lai & Vinh Thanh \\
\hline Average \# drugs & 4.1 & 4.3 & 4.1 & 4.1 & 3.3 & 4.2 & 4.6 & 4.7 & 3.9 \\
\hline$\%$ Generic & 94.2 & 100 & 84.4 & 100 & 100 & 79.3 & 90.1 & 100 & 99.09 \\
\hline$\%$ Antibiotics & 85.8 & 94.6 & 86.4 & 99.1 & 40.9 & 90.9 & 85.5 & 95.5 & 93.6 \\
\hline$\%$ essential drugs & 78.74 & 80.2 & 79.0 & 79.8 & 70.1 & 80.1 & 76.9 & 84.6 & 79.1 \\
\hline$\%$ corticoid & 41.7 & 33.6 & 58.2 & 36.4 & 13.6 & 42.7 & 50.9 & 43.6 & 54.6 \\
\hline$\%$ vitamin & 13.1 & 3.6 & 3.6 & 5.5 & 2.7 & 29.1 & 38.2 & 17.3 & 4.6 \\
\hline
\end{tabular}


Table 2: The results of supplementary prescribing indicators

\begin{tabular}{|c|c|c|c|c|c|c|c|c|c|}
\hline & Mean & Binh Thuy & Cai Rang & O Mon & Thot Not & Co Đo & Phong Đien & Thoi Lai & Vinh Thanh \\
\hline Cost/encounter & 37.52 & 40.07 & 57.96 & 30.40 & 11.17 & 35.79 & $35.05^{\circ}$ & 48.80 & 40.93 \\
\hline$\%$ costs spent on antibiotics & 55.20 & 68.21 & 60.68 & 62.50 & 26.20 & 53.92 & 53.59 & 61.52 & 54.95 \\
\hline$\%$ costs spent on essential drugs & 75.70 & 81.30 & 83.33 & 77.97 & 57.99 & 73.23 & 72.90 & 82.38 & 76.47 \\
\hline$\%$ costs spent on corticoid & 1.91 & 2.40 & 2.05 & 2.20 & 0.54 & 2.19 & 2.02 & 1.89 & 1.99 \\
\hline$\%$ costs spent on vitamin & 1.43 & 0.18 & 0.52 & 0.30 & 0.47 & 7.03 & 1.71 & 0.74 & 0.46 \\
\hline
\end{tabular}

\section{DISCUSSION}

The average number of drugs per encounter was 4.13 , which is higher than the WHO recommendation of 2-3, the study in Southern Ethiopia of 1.58 [5], in Umm Al Quwain of 2.6 [6], and in India of 3.32 [7], while lower than Akhtar's research of 5.61 [8]. It is preferable to keep the number of drugs per prescription as low as possible since higher fig. lead to increases in risk of drug interactions, hospital cost, and errors of prescribing. Vietnam is a hot and humid country. Sudden changes in the weather make people more susceptible to many kinds of diseases at the same time, especially children. Most children come to the clinic with many signs and overlapping symptoms of various diseases, requiring a combination of drugs [9]. That leads to more diagnoses were made in the children's prescription and the treatment becomes more complicated.

Percentage of drugs prescribed by generic name was $94.21 \%$, which is lower than that of the WHO recommendation of $100 \%$ while much higher than another results of 2.63\% [8], 7.4\% [10] and 76.34\% [7]. Under the terms of medical and pharmacy training publications are used by the generic name. Therefore, the scientific knowledge of the doctor prescribes focus on this name. Regular use of the original name of medicines will help prescribers to use their knowledge about the basic pharmacological effects of the drug to optimize and avoid confusion in prescribing. In addition, if the doctor prescribed a trade name, there would be delays in dispensing the drug to the patient when the particular name is not available in the allocation. The prescription of the original name will avoid this situation [11]. In general, the results of this study have shown that physicians have complied with the prescription regulations better, especially prescriptions by name, contributing to the goal of prescribing and using rational and safe drugs.

Percentage of encounters with an antibiotic prescribed was $85.80 \%$, which is higher than that of the WHO recommendation $(<30 \%)$, a study in Southern Ethiopia (79.8\%) [12] and the result of $81.12 \%$ in India [8]. This can be explained as follows: Vietnam belongs to the group of countries with a humid and tropical monsoon climate, the weather usually changes. Children are less adaptable to the constant change of weather, so they are more susceptible to diseases, especially respiratory diseases. This made the doctor have to use antibiotics for the children. However, antibiotics are a special class of drug because their use affects not only the patient but also the community. To ensure the proper use of drugs, knowledge about antibiotics, pathogens and patients should be mastered. In the coming time, hospitals need to strengthen the direction, inspection and supervision of the drug and treatment committee, the medical examination and treatment, analysis and use of drugs in clinical cases in order to limit the abuse of antibiotics and improve the quality of treatment.

Percentage of drugs prescribed from the essential drugs list by Ministry of Health is $78.74 \%$ on average. This value is lower than which of the WHO recommendation (100\%) and the finding in India (90.23\%) [8]. Good practice on the essential drug policy may help to manage and designate more appropriate and safer drug use guidelines, making budget use more effective, and especially, financial resources are limited [9].

Percentage of encounters with a corticoid prescribed is $41.71 \%$. Corticoids are commonly prescribed as anti-inflammatory and immunosuppressant medicines. Studies in adults and children showed that the combination of corticoid and antibiotics in acute pharyngitis help to relieve pain and recover faster. As a result of easy availability and relief activity, they are identified as one of the oral drugs regularly abused by the patients. Moreover, adverse effects of corticosteroids are widely recognized, so it should be cautious in use [13].
The percentage of encounters with vitamin prescribedwas $13.07 \%$. Nowadays, vitamins are a group of drugs that are considered safe. However, if the prescription of vitaminwas abused, this would increase the cost of medical payment and side effects appearance. Moreover, an unnecessary appearance of vitamin can sometimes give rise todrug interactions, which affect the health of patient [14].

The average drug cost per encounter was 37.52 thousand VND $(p<0.001)-i . e .$, the price of each prescription is not so high. This result is lower than that compared to Indian [8]. This is partly due to the fact that the doctor's prescription is mainlytaken from the list of essential drugs that are cheap but stillbe guaranteein quality. In addition, hospitals mainlyused drugs from the tender list. New regulations on drug tender have ensured that both the quality and price of medicines and saved $35 \%$ of the costs of drug purchasing in the medical market place. Therefore, the average drug cost per encounteris not high, contributing to the reduction of medical expenses of burden.

The percentage of drug costs spent on antibiotics was $55.20 \%$ $(p<0.001)$ which is similar to the finding in Indian [8]. It can be seen that the cost of antibiotics is always high in prescriptions because antibiotics are the most important drug in the treatment of inflammation. Disease patterns in Vietnam have a high prevalence of bacterial infections and antibiotic using is still widespread. Therefore, to reduce the rate of antibiotic drug prices, doctors need to use antibioticsproperlyandpriority should be given to select the most effective and affordable antibiotics.

The percentage of drug costs spent on essential drugs by the Ministry of Health was $75.70 \%$ on average $(p<0.001)$. Essential drugs account for a high proportion in the list of drugs mainly used in hospitals, so the percentage of essential drugs also accounted for a quite high amount of prescription drugs. It also showed that the prescription ofphysicians has a preference for more essential drugs than non-essential drugs, contributing to the implementation of the National Drug Policy.

The percentage of drug costs spent on corticoid was 1.91\% $(p<0.001)$. In the study, the percentage of prescription drugs containing corticoid was $41.71 \%$ on average and in terms of price, only accounted for $1.91 \%$. Thereby, corticoid is a relatively inexpensive drug that makes the prescription for most people is easy. Additionally, the number ofsteroid-contained encounters is very high that may lead todrug abuse.

The percentage of drug costs spent on vitamin was $1.43 \%(\mathrm{p}<0.001)$. Vitamin supplements tend to decrease. This is also a good thing because physicians are more aware of using vitamin supplements.

\section{CONCLUSION}

The study investigated prescription indicators according to WHO standards at 8 local hospitals in Cantho city in the year 2015 and 2016. Prescription indicators were not really consistent with the recommendation of WHO and the influence of many different evaluated factors. This result provides implications for health providers aiming at improving drug use rationally and focusing on the essentials to promote safe, effective and reasonable use of drugs. Intervention studies and another drug use indicators of WHO on peadiatric patients should be carried out.

\section{AUTHORS CONTRIBUTIONS}

Hung Phuc Nguyen designed the study and collected the data. Huong Vo Thi My analyzed the data. Thanh Phan Chi prepared the manuscript and revision. All authors approved the final version submitted. 


\section{CONFLICTS OF INTERESTS}

The authors do not have any conflict of interest

\section{REFERENCES}

1. P Nikhithasri, M Ramya. Assessment of medication errors in peadiatric inpatient department of a private hospital. Int J Curr Pharm Res 2017;9 Suppl 6:70-5.

2. Thang Tran Nhan. Assessment of outpatient drug prescription at Bachmai Hospital in 2011. J Practical Med 2012;830:24-8.

3. WHO. Promoting the safety of medicines for children. WHO Library Cataloguing-in-Publication Data; 2007. p. 24.

4. WHO. Department of essential medicines and drug policy, Guide to survey of drug usage in medical center, Geneve. Medicine Publication; 1999.

5. Minyahil A Woldu, Sultan Suleman. Retrospective study of the pattern of antibiotic use in Hawassa University Referral Hospital Peadiatric Ward, Southern Ethiopia. J Appl Pharm Sci 2013;3 Suppl 2:93-8.

6. Suleiman I Sharif, Aseel H Nassar. Trends of peadiatric outpatients prescribing in umm al quwain, United Arab Emirates. Pharmacol Pharm 2015;6:9-16.
7. Balaji R, Sekkizhar M. An observational study of drug utilization pattern pharmacovigilance of antipsychotics. Int Curr Pharm Res 2017;9 Suppl 6:56-62.

8. MS Akhtar, Divya Vohora. Drug prescribing practices in peadiatric department of a north Indian university teaching hospital. Asian J Pharm Clinical Res 2012;5 Suppl 1:146-9.

9. WHO. IMCI Integrated Management of Childhood Illness. WHO Library cataloging-in-publication Data; 2005.

10. WHO. Promoting safety of medicines for children. WHO Library Cataloguing-in-Publication Data; 2007. p. 24.

11. St James's Hospital. Generic prescribing. National medicines information centre; 2009. p. 15.

12. Minyahil A Woldu, Sultan Suleman. Retrospective study of the pattern of antibiotic use in Hawassa University referral hospital peadiatric Ward, Southern Ethiopia. J Appl Pharm Sci 2013;3 Suppl 2:93-8.

13. Kavitha Pawar, Alamelu Haran. Multiple adverse effects of betamethasone used as self-medication: a case report. Asian J Pharm Clin Res 2015;8 Suppl 2:11-2.

14. Mejo C Korah, Junaid Rahman PV. Adverse effects and side effects on vitamin therapy: a review. Asian J Pharm Clin Res 2017;10 Suppl 5:19-26. 